\title{
Transcriptome profile of human neuroblastoma cells in the hypomagnetic field
}

\author{
MO WeiChuan ${ }^{1,2}$, LIU Ying $^{1 *}$, BARTLETT Perry $^{2 *} \&$ HE RongQiao ${ }^{1}$ \\ ${ }^{1}$ Institute of Biophysics, Chinese Academy of Sciences, Beijing 100101, China; \\ ${ }^{2}$ Queensland Brain Institute, The University of Queensland, Brisbane, Queensland 4072, Australia
}

Received January 15, 2014; accepted February 25, 2014; published online March 19, 2014

\begin{abstract}
Research has shown that the hypomagnetic field (HMF) can affect embryo development, cell proliferation, learning and memory, and in vitro tubulin assembly. In the present study, we aimed to elucidate the molecular mechanism by which the HMF exerts its effect, by comparing the transcriptome profiles of human neuroblastoma cells exposed to either the HMF or the geomagnetic field. A total of 2464 differentially expressed genes (DEGs) were identified, 216 of which were up-regulated and 2248 of which were down-regulated after exposure to the HMF. These DEGs were found to be significantly clustered into several key processes, namely macromolecule localization, protein transport, RNA processing, and brain function. Seventeen DEGs were verified by real-time quantitative PCR, and the expression levels of nine of these DEGs were measured every $6 \mathrm{~h}$. Most notably, MAPK1 and CRY2, showed significant up- and down-regulation, respectively, during the first $6 \mathrm{~h}$ of $\mathrm{HMF}$ exposure, which suggests involvement of the MAPK pathway and cryptochrome in the early bio-HMF response. Our results provide insights into the molecular mechanisms underlying the observed biological effects of the HMF.
\end{abstract}

hypomagnetic field, geomagnetic field, transcriptome profile, massively parallel sequencing, MAPK1, CRY2

Citation: Mo WC, Liu Y, Bartlett PF, He RQ. Transcriptome profile of human neuroblastoma cells in the hypomagnetic field. Sci China Life Sci, 2014, 57: 448-461, doi: 10.1007/s11427-014-4644-Z

Many vertebrates, such as migratory birds and sea turtles, can sense the Earth's magnetic field (geomagnetic field, GMF) for positional and directional information during long-distance migration [1,2]. Previous studies have shown that without the local GMF, the hypomagnetic field (HMF) interferes with many biological functions. Exposure to the HMF has been shown to have adverse effects on embryonic development and brain function [3-5]. HMF exposure has also been shown to lead to increased occurrences of developmental abnormalities in the newt and Xenopus laevis [6,7], alteration of the vocal behavior [8] and circadian rhythm of birds [9] and rats [10], dysfunction in the learning and memory of Drosophila and chicks [11-13], and a re-

*Corresponding author (email: liuy@moon.ibp.ac.cn; p.bartlett@uq.edu.au) duction in stress-induced analgesia in mice [14-16]. There are reports indicating that even short-term HMF exposure can increase the number of errors and the task processing time of human subjects during learning [17]. Given that the HMF is a key environmental factor of outer space, increasing research attention is being directed toward understanding the biological effects of the HMF, as this knowledge may lead to improvements in healthcare for astronauts [5,18]. At the cellular and molecular level, in vitro and in vivo studies have shown that cell cycle progression, tubulin assembly, DNA super condensation and $\mathrm{H}_{2} \mathrm{O}_{2}$ production are potential targets of the HMF [18-23]. Based on the radical-pair reaction theory, cryptochrome genes (CRYs) have been proposed to be the putative magnetoreceptor genes, which enable an organism to detect magnetic fields [24-26]. 
Nevertheless, the importance of CRYs in determining the effects of HMF has not been examined in animal cells. Thus, although the biological effects of the HMF are becoming more well-documented, the cellular and molecular mechanisms underlying the effect of the HMF remain unclear.

Quantitative transcriptomic methods are widely used for understanding and assessing changes in cellular and molecular activity in response to changes in the environment $[27,28]$. Massively parallel sequencing technology, namely deep sequencing, is a powerful method for investigating DNA expression patterns. This technology has most recently been used to evaluate transcriptomic changes in mosquitoes under different environmental conditions, screen for the pathways involved in neurodevelopment and neurodegeneration, predict drug resistance genes for hepatitis, and understand the cellular mechanisms involved in irradiationinduced tumorigenesis [29-32]. Deciphering the transcriptomic responses to HMF exposure would allow for the identification of key genes involved in the processes of HMF-response/GMF-adaptation, and may ultimately lead to the development of effective counter-measures to prevent the adverse effects of the HMF.

We previously found that $2 \mathrm{~d}$ of exposure to the HMF accelerates the proliferation of human neuroblastoma cells (SH-SY5Y cell line), and predicted that the G1/S transition plays an important role in the bio-HMF response [18]. In the present study, to identify the HMF responding genes in neuronal cells, we collected RNA samples from SH-SY5Y cells after $2 \mathrm{~d}$ of culturing in a permalloy magnetic shielding system, where they were exposed to either the HMF $(<200 \mathrm{nT})$ or GMF $(\sim 15 \mu \mathrm{T})$, after which the RNA was sent for massively parallel sequencing based on Illumina/Solexa sequencing [33]. Compared to controls, 2464 differentially expressed genes (DEGs) were identified, of which 216 were up-regulated and 2248 were down-regulated. Real-time quantitative PCR (RT-qPCR) was used to identify and verify the DEGs. Also, the dynamic expression changes of selected DEGs during the incubation period were measured. Our results provide some insight into the mechanisms underlying the effects of the HMF.

\section{Materials and methods}

\subsection{The HMF condition}

The HMF cell culture conditions were established using a GMF shielding system, as described previously [18,34]. The decay efficiency of the GMF shielding box for the DC magnetic field was $\sim 40 \mathrm{~dB}$. The HMF-exposed cells were cultured in an environment with a residue magnetic field lower than $200 \mathrm{nT}(111.1 \pm 14.9 \mathrm{nT})$. The control cells were incubated in an environment where the average intensity of magnetic field was $15.1 \pm 2.2 \mu \mathrm{T}$. The decay efficiency of the
GMF shielding box for the AC magnetic field was $\sim 34 \mathrm{~dB}$. The AC field in the control environment was $575.7 \pm 29.1 \mathrm{nT}$. The AC field inside the GMF shielding box was $12.0 \pm 0.0$ nT. The predominant frequency was $50 \mathrm{~Hz}$. The incubation conditions $\left(37^{\circ} \mathrm{C}, 5 \% \mathrm{CO}_{2}\right.$ and $>95 \%$ relative humidity) were unified by air circulation between the GMF shielding chamber and the control space. The DC magnetic fields were measured using an APS Model 520 3-Axis Fluxgate Magnetometer (Applied Physics Systems, USA). The ambient AC fields were measured using a CCG-1000 induction alternative magnetometer (National Institute of Metrology, China). The predominant AC field frequency was checked using a Textronics TDS 2014 digital real-time oscilloscope (Tequipment.NET, USA). The cell incubation conditions were identical to those described previously [18].

\subsection{Cell culture}

Human neuroblastoma cells (SH-SY5Y cell line; China Cell Resource Confederation) were maintained in DMEM (High D-glucose) (Gibco/Invitrogen, USA) supplemented with $10 \%$ fetal bovine serum (FBS; PAA Laboratories, Austria), 100 unit $\mathrm{mL}^{-1}$ penicillin and $100 \mu \mathrm{g} \mathrm{mL}^{-1}$ streptomycin (Gibco/Invitrogen) as a monolayer in petri dishes (NEST Biotechnology, China), and the medium was replaced every 2 d. Cells were detached at sub-confluence with trypsinEDTA solution $(0.25 \%$ Trypsin, $0.25 \%$ EDTA; Sigma-Aldrich, USA) and re-seeded for subsequent steps.

\subsection{RNA extraction}

Cells were seeded at $1.5 \times 10^{4} \mathrm{~cm}^{-2}$ in $60 \mathrm{~mm}$ petri dishes and transferred to the HMF/GMF immediately. Total RNA was extracted using TRIzol reagent (Invitrogen), following the manufacturer's instructions. RNA samples were dissolved in diethylpyrocarbonate-treated water (DEPC; Sigma-Aldrich), and the concentrations were determined spectroscopically with a Biophotometer (Eppendorf, Germany). Total RNA from four parallel experiments was used for Solexa sequencing. RNA samples from three parallel experiments at each time point were collected for dynamic gene expression analysis.

\subsection{Solexa sequencing}

Total RNA (20 $\mu \mathrm{g})$ samples were sent to the Beijing Genomics Institute (BGI) for Solexa sequencing (commercial service). Initially, poly(A) mRNA molecules were purified from total RNA samples by poly(T) oligo-attached magnetic beads, and double-stranded cDNA was synthesized with an oligo(dT) primed reverse-transcript reaction. The cDNA molecules were fragmented with restriction endonucleases Nla III and Mme I. The fragments were precipitated with 
magnetic beads and adaptors were added to the $3^{\prime}$ and $5^{\prime}$ ends of each fragment, generating the sequencing tags. Purified single-strand tag molecules were loaded and fixed on a Solexa sequencing chip (flowcell) for Solexa sequencing on a genome analyzer (Illumina, USA). Mono-molecule clusters were generated by in situ amplification and sequenced with the sequencing by synthesis method.

\subsection{Gene annotation}

Before gene annotation, empty reads (adaptor sequence only), low-quality reads (unknown nucleotide), substandard-length reads, and single copy reads were filtered out. The clean tags were mapped to the human genome sequence NCBI build 36.3 by SOAP [35], allowing no more than two mismatches (Shanghai Qiming). The copy numbers of genes mapped by unambiguous tags (one tag onto one gene) were also determined using the software package SOAP. The expression levels of the annotated genes in the HMF and GMF samples were examined using the false discovery rate (FDR) modified Poisson distribution assay. The DEGs were screened using the cutoffs of $\mid \log _{2}$ Ratio $\mid \geqslant 1$ and FDR $\leqslant 0.001$ $[36,37]$. The relationship graph of the selected DEGs was plotted using Medusa software [38].

\subsection{Gene ontology (GO) analysis}

GO analysis was applied to analyze the main functions of the DEGs according to the Gene Ontology database (http://www.geneontology.org/) [39,40]. Generally, Fisher's exact test and $\chi^{2}$ test were used to classify the GO category. The FDR was calculated to correct the $P$-value [41]. $P$-values for the GOs of all the DEGs were calculated. Enrichment provided a measure of the significance of the function: as the enrichment increased, the corresponding function is more specific, allowing for the identification of GOs with more concrete function descriptions. Within the significant category, the enrichment $\operatorname{Re}$ was given by $\operatorname{Re}=\left(n_{f}\right.$ $/ n) /\left(N_{f} / N\right)$, where $n_{f}$ is the number of DEGs within the particular category, $n$ is the total number of genes within the same category, $N_{f}$ is the number of DEGs in the entire expression profile, and $N$ is the total number of genes in the expression profile [42].

\subsection{Pathway analysis}

Pathway analysis was used to identify the significant pathways of the DEGs according to the Kyoto Encyclopedia of Genes and Genomes (KEGG) (http://www.genome.jp/ kegg/), Biocarta (http://www.biocarta.com/) and Reactome (http://www.reactome.org) databases. Fisher's exact test and $\chi^{2}$ test were used to select the significant pathway, and the threshold of significance was determined at $P<0.05$.
The enrichment, Re, was calculated as per the equation above [43-45].

\section{8 qPCR analysis}

In brief, a first-strand cDNA fragment was synthesized from total RNA using an EasyScript First-Strand cDNA Synthesis SuperMix (TransGen Biotech, China). The gene specific primers were designed by PrimerBank (http://pga.mgh. harvard.edu/primerbank) [46] and synthesized commercially (Shanghai Sangon Biological Engineering Technology \& Services). The primers are listed in Table 1. The $20 \mu \mathrm{L}$ qPCR samples were run in triplicate on an MJ Research Chromo4 detector (Bio-Rad Laboratories, USA) and Opticon Monitor2 software using $1 \mu \mathrm{L}$ first-strand cDNAs and TransStart Green qPCR SuperMix UDG kit (TransGen Biotech). Thermal cycling was performed at an initial UDG incubation step at $50^{\circ} \mathrm{C}$ and a UDG inactivation step at $94^{\circ} \mathrm{C}$, and then subjected to 45 cycles of $15 \mathrm{~s}$ denaturing at $95^{\circ} \mathrm{C}, 30 \mathrm{~s}$ at annealing temperature, and $30 \mathrm{~s}$ extension at $72^{\circ} \mathrm{C}$. Since $\alpha$-tubulin was not differentially expressed, the relative quantitation of gene expression was normalized to $\alpha$-tubulin (Figure S1 in Supporting Information).

For the verification of the expression of the DEGs, the cDNA templates were prepared with the individual total RNA samples, which were the same for the mixture sent for Solexa sequencing. DEGs that showed consistent changes in at least three samples of the parallel experiments were considered as verified. For the evaluation of the dynamic expression patterns of selected DEGs, total RNA samples were collected in the HMF and GMF at 6, 12, 18, 24, 30, and $36 \mathrm{~h}$. The expression of HMF sample genes was normalized to the corresponding GMF control. The fold change in the dynamic gene expression assay was plotted against the sampling time.

\subsection{Statistical analysis}

Each experiment was repeated at least twice with triplicate samples for the qPCR assay. Means are expressed as mean \pm standard error of the mean (SEM). One-way ANOVA was applied for mean comparison. Differences were considered to be significant when $P<0.05$.

\section{Results}

\subsection{Solexa sequencing}

After $2 \mathrm{~d}$ of exposure to either the HMF or GMF, RNA samples were collected for Solexa sequencing. 5.39 million 35 bp raw reads were generated from the mixture sample of the HMF group, and 7.97 million raw reads were generated from the mixture sample of the GMF group, until the per- 
Table 1 The primers used for qPCR assay

\begin{tabular}{|c|c|c|c|c|}
\hline Gene & Primer & Sequence $\left(5^{\prime}\right.$ to $\left.3^{\prime}\right)$ & $T_{\mathrm{m}}\left({ }^{\circ} \mathrm{C}\right)$ & Length (bp) \\
\hline \multirow[t]{2}{*}{$\alpha$-tubulin } & forward & ACCTTAACCGCCTTATTAGCC & \multirow{2}{*}{52} & \multirow{2}{*}{288} \\
\hline & reverse & CACCACGGTACAACAGGCA & & \\
\hline \multirow[t]{2}{*}{ CCNI } & forward & TTTTCCATGCCATTGCAGTGT & \multirow{2}{*}{52} & \multirow{2}{*}{113} \\
\hline & reverse & GGCCATACAGTGAAGTAGTTGC & & \\
\hline \multirow[t]{2}{*}{ CCAR1 } & forward & AGGCCCTGTATAGTGTGCAAC & \multirow{2}{*}{52} & \multirow{2}{*}{190} \\
\hline & reverse & CCTGTGAAAACACGCTGCTT & & \\
\hline \multirow[t]{2}{*}{ TCF7L2 } & forward & TCGCTCCGAAAGTTTCCGAG & \multirow{2}{*}{58} & \multirow{2}{*}{195} \\
\hline & reverse & GTGCTGCCGGACTGAAAATG & & \\
\hline \multirow[t]{2}{*}{ HTRID } & forward & AACTACCTGATTGGCTCCCTG & \multirow{2}{*}{52} & \multirow{2}{*}{123} \\
\hline & reverse & CCAGATGTCACACAAGATTTGGC & & \\
\hline \multirow[t]{2}{*}{ SAP3O } & forward & GAGCTGGATAAGAGCGCAAGG & \multirow{2}{*}{52} & \multirow{2}{*}{210} \\
\hline & reverse & TCTGGTTGGTAGCTTGAAGTGT & & \\
\hline \multirow[t]{2}{*}{ WASL } & forward & GAACGAGTCCCTCTTCACTTTC & \multirow{2}{*}{50} & \multirow{2}{*}{110} \\
\hline & reverse & CACTGCACTTCTTTGACCACATA & & \\
\hline \multirow[t]{2}{*}{ SAP18 } & forward & GATGGATGCAACCTTGAAAGAAC & \multirow{2}{*}{52} & \multirow{2}{*}{131} \\
\hline & reverse & CCTTAACTCGATAGCCAGGTCT & & \\
\hline \multirow[t]{2}{*}{ ATF1 } & forward & GAAGATTCCCACAAGAGTACCAC & \multirow{2}{*}{52} & \multirow{2}{*}{144} \\
\hline & reverse & GCCTATGCTGTCGGATGAGTC & & \\
\hline \multirow[t]{2}{*}{$M S N$} & forward & AAGACTGCCATGAGTACACCT & 52 & 145 \\
\hline & reverse & CCTCAGTGGTACGTTCCTCC & 32 & $14 J$ \\
\hline CYP51A1 & forward & TCCAGGACATCAGGTGTGTGT & 52 & 136 \\
\hline & reverse & TGGCACATAGGCAAACTTTTCC & 52 & 150 \\
\hline$G M F B$ & forward & AACGACAACCTCGCTTCATTG & 52 & 212 \\
\hline & reverse & CCATTCTTCAGTTAGGTCTTCGG & 52 & 212 \\
\hline$E 2 F 3$ & forward & CGGTCATCAGTACCTCTCAGA & 52 & 114 \\
\hline & reverse & AGACGTATCATACCGCGTTTTT & 52 & 114 \\
\hline SRSF2IP & forward & CAAGGAGGTCTACACGTAACAC & 50 & 159 \\
\hline & reverse & TTGGAGCCTGTCTTGTTTGCT & & \\
\hline TOP $2 A$ & forward & ATTAGTGACCCAGCAAATGTGG & 50 & 124 \\
\hline & reverse & GGTCCCTTTGTTTGTTGTCCG & 50 & 134 \\
\hline RAPGEF2 & forward & GTTATGGTGAAAGAACACCGAGA & 50 & 216 \\
\hline & reverse & CGGGTCATTAAACCACTCCAATA & 30 & 210 \\
\hline$C R Y 2$ & forward & CGTGTTCCCAAGGCTGTTCA & 50 & 136 \\
\hline & reverse & CTCCGTCACTACTTCCACACC & 52 & 150 \\
\hline MAPK1 & forward & TACACCAACCTCTCGTACATCG & 52 & 160 \\
\hline & reverse & CATGTCTGAAGCGCAGTAAGATT & 52 & 109 \\
\hline
\end{tabular}

centage of genes identified had become stagnant (Figure S2 in Supporting Information). 4.93 million HMF clean tags (182922 distinct tags) and 7.39 million GMF clean tags (240872 distinct tags) were obtained. Of these tags, 16759 of the distinct HMF clean tags and 28061 of the distinct GMF clean tags were mapped to 11094 and 15531 genes, respectively, in the human mRNA library (Table 2). It should be noted that after $2 \mathrm{~d}$ of incubation, there were significantly more cells in the HMF group compared to the GMF control group $(P=0.03)$ (Figure S3 in Supporting Information).

\subsection{Identification of DEGs}

After exposure to the HMF, based on the DEG screening criteria, 216 genes were found to be up-regulated and 2248 down-regulated (Figure 1). The general gene ontogeny (GO) analysis of the DEGs is presented in Figure 2. The main functions of the up-regulated genes were related to transport of ions and neurotransmitters $(26 \%)$, metabolic processes (20\%), cell proliferation and development (16\%), immuno-

Table 2 The total number of sequencing reads obtained from each sample

\begin{tabular}{crr}
\hline Category & HMF & GMF \\
\hline Clean tag (reads) & 4934900 & 7389471 \\
Clean tag (distinct tags) & 182922 & 240872 \\
Mapping to gene (distinct tags) & 16756 & 28061 \\
Perfect match (distinct tags) & 6203 & 7611 \\
1 bp mismatch (distinct tags) & 1337 & 3115 \\
2 bp mismatch (distinct tags) & 9216 & 17335 \\
Unknown tag (distinct tags) & 132173 & 173155 \\
\hline
\end{tabular}



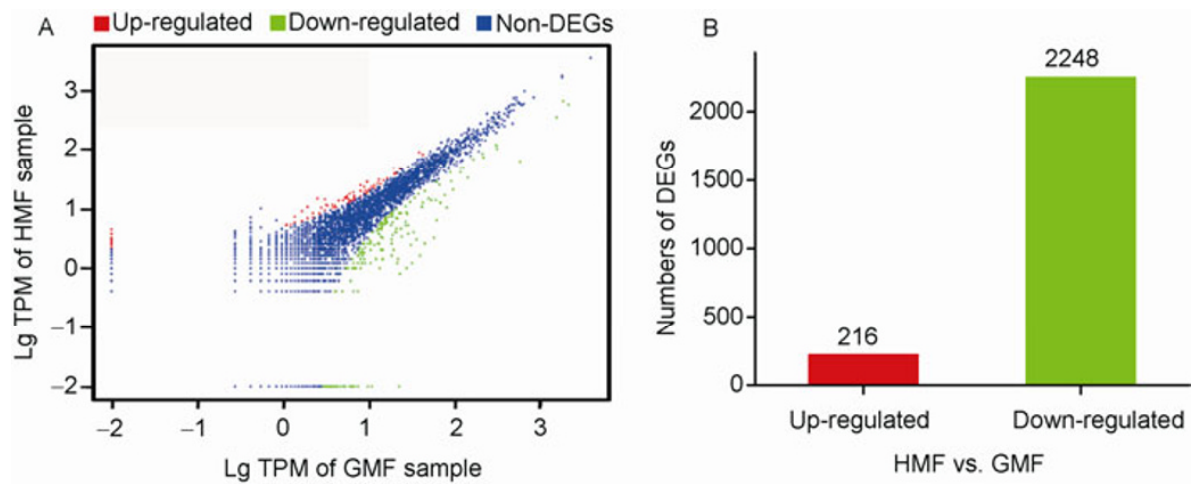

Figure 1 Identification of DEGs. A, Tag expression level. Geomagnetic field (GMF) sample vs. hypomagnetic field (HMF) sample. Up-regulated DEGs are represented by red dots, down-regulated DEGs by green dots, and non-DEGs by blue dots. FDR $<0.001$ and $\mid \log _{2}$ Ratio $\mid \geqslant 1$. TPM, tag per million. B, Numbers of DEGs. Red, up-regulated; green, down-regulated.
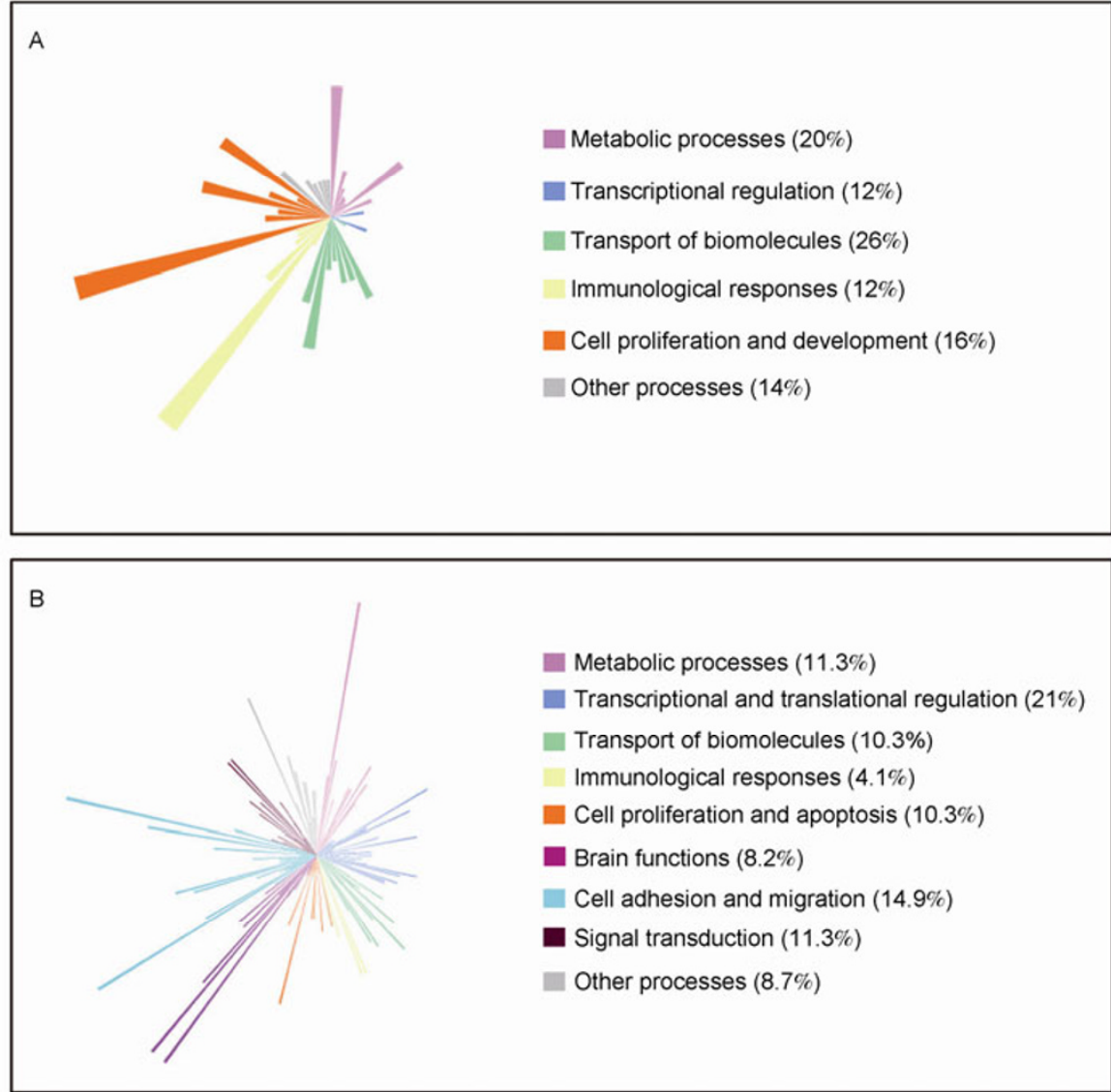

Figure 2 General GO analysis. A, The up-regulated categories. B, The down-regulated categories. The main clustered categories are indicated using different colors. The percentage represented by each category is shown in brackets. The radial lengths are the relative enrichment values of the terms.

logical responses $(12 \%)$, and transcriptional regulation $(12 \%)$ (Figure 2A). The main functions of the down- regulated genes were related to transcriptional and translational regulation (21\%), cell adhesion and migration $(14.9 \%)$, metabolic processes $(11.3 \%)$, transport of biomolecules $(10.3 \%)$, cell proliferation and apoptosis $(10.3 \%)$, signal transduction $(11.3 \%)$, and brain function $(8.2 \%)$ (Figure 2B). By limiting the mapping category to the terms "cell proliferation" and "apoptosis", six up-regulated terms and 35 down-regulated terms were mapped (Figure 3). Of the terms that were positive for cell proliferation (19.5\%), all of the associated genes were down-regulated. Of the terms that were negative for cell proliferation $(31.7 \%)$, the associated genes were either up- or down-regulated.

Using pathway analysis, nine up-regulated pathways and 57 down-regulated pathways were identified (Figure 4). The 


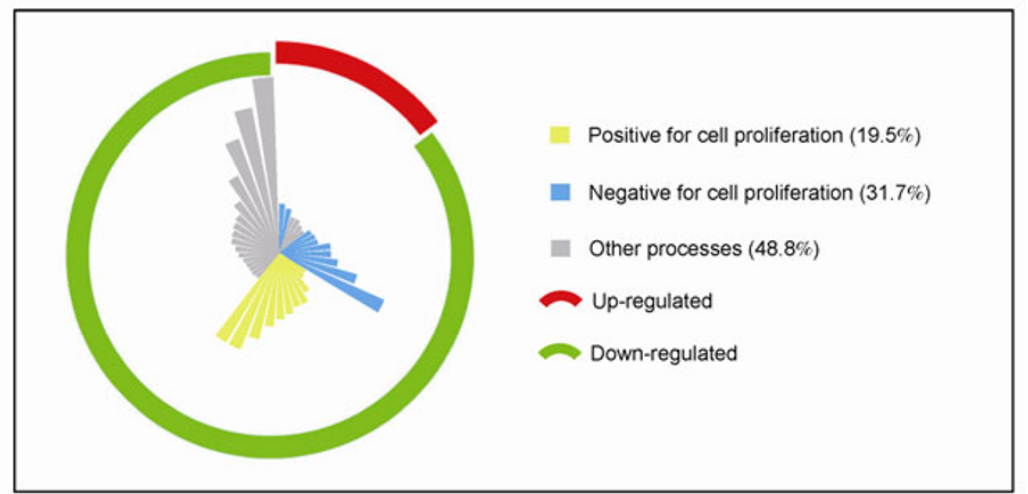

Figure 3 GO analysis on cell proliferation. The GO analysis was restricted to the category of "cell proliferation" and "apoptosis". The pro-proliferation and anti-apoptosis terms are labeled "positive for cell proliferation". The anti-proliferation and pro-apoptosis terms are labeled "negative for cell proliferation". The yellow columns are categories positive for cell proliferation. The blue columns are categories negative for cell proliferation. The grey columns are other processes. The radial lengths are the relative enrichment values of the terms. A red and a green arc indicate the up-regulated and down-regulated terms, respectively.
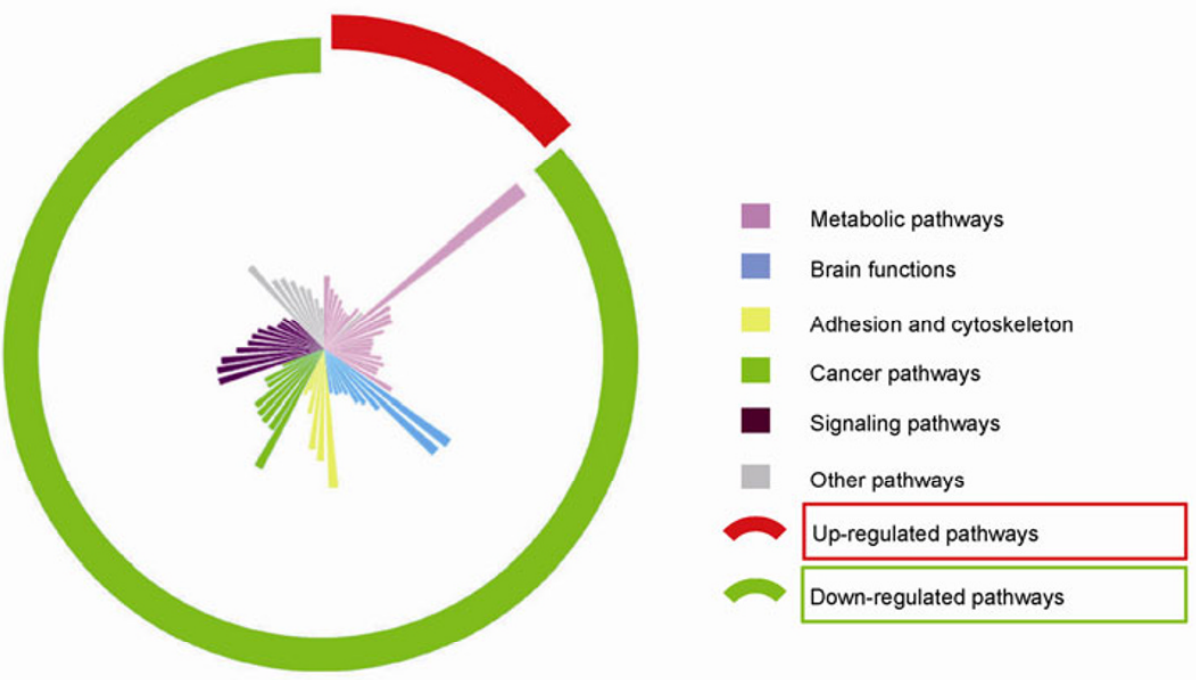

\begin{tabular}{|c|c|c|}
\hline $\begin{array}{l}=\text { Biosynthesis of unsaturated fatty acids } \\
=\text { Metabolic pathways } \\
=\text { Drug metabolism - cytochrome P450 }\end{array}$ & $\begin{array}{l}\text { = Cysteine and methionine metabolism } \\
\text { = Glycolysis / Gluconeogenesis } \\
\text { = Ubiquitin mediated proteolysis }\end{array}$ & $\begin{array}{l}\text { " Pyruvate metabolism } \\
\equiv \text { Caffeine metabolism } \\
\equiv \text { Notch signaling pathway }\end{array}$ \\
\hline Metabolic pathways & Pyrimidine metabolism & Taurine and hypotaurine metabolism \\
\hline Cysteine and methionine metabolism & Ubiquitin mediated proteolysis & Biosynthesis of plant hormones \\
\hline Elycerophospholipid metabolism & alpha-Linolenic acid metabolism & Ether lipid metabolism \\
\hline E Glycolysis / Gluconeogenesis & Galactose metabolism & N-Glycan biosynthesis \\
\hline = Type I diabetes mellitus & Oxidative phosphorylation & Huntington's disease \\
\hline Alzheimer's disease & " Parkinson's disease & Axon guidance \\
\hline = Circadian rhythm - mammal & Olfactory transduction & E Long-term potentiation \\
\hline Long-term depression & Prion diseases & Focal adhesion \\
\hline Regulation of actin cytoskeleton & Adherens junction & Gap junction \\
\hline Leukocyte transendothelial migration & Tight junction & Renal cell carcinoma \\
\hline = Glioma & Pathways in cancer & Endometrial cancer \\
\hline Non-small cell lung cancer & Prostate cancer & Melanoma \\
\hline Chronic myeloid leukemia & Insulin signaling pathway & ErbB signaling pathway \\
\hline - Neurotrophin signaling pathway & MAPK signaling pathway & a Fc epsilon RI signaling pathway \\
\hline EnRH signaling pathway & a Chemokine signaling pathway & - VEGF signaling pathway \\
\hline - Wnt signaling pathway & - TGF-beta signaling pathway & - T cell receptor signaling pathway \\
\hline - B cell receptor signaling pathway & Natural killer cell mediated cytotoxicity & Endocytosis \\
\hline RNA polymerase & Eell cycle & a Pathogenic Escherichia coli infection - EHEC \\
\hline = Dorso-ventral axis formation & Eibosome & Eardiac muscle contraction \\
\hline
\end{tabular}

Figure 4 Significantly clustered pathways. The pink columns represent the metabolic pathways. The blue columns represent pathways related to brain function. The yellow columns are pathways related to cell adhesion and the cytoskeleton. The green columns represent cancer pathways. The purple columns represent signaling pathways. The grey columns represent other pathways. The radial lengths are the relative enrichment values of the pathways. The up-regulated terms are indicated by a red arc and are listed in the red rectangle. The down-regulated terms are indicated by a green arc and listed in the green rectangle. 
up-regulated pathways related to metabolic pathways (8/9) and the notch signaling pathway (1/9). The main downregulated pathways were related to metabolic pathways (14/57), signaling pathways (12/57), brain function (9/57), cancer pathways (8/57), and adhesion and the regulation of the assembly of the cytoskeleton (6/57).

\subsection{Verification of DEGs}

We verified the expression of 30 DEGs with functions closely related to the main clustered GO annotations and pathways (Table 3), with the individual HMF and GMF RNA samples for the sequencing analysis. The expression of 17 genes were in agreement with the sequencing results (Figure 5). Of these 17 verified DEGs, MAPK1 was found to be involved in 30 significantly clustered down-regulated pathways. The remaining DEGs were involved in no more than two pathways (Table S1 in Supporting Information).

\subsection{Dynamic mRNA expression}

The dynamic mRNA expression patterns of nine validated DEGs (CRY2, CCAR1, CCNI, E2F3, TCF7L2, TOP2A,
SAP18, SAP30, and MAPK1), which are more closely related to the terms "cell proliferation" and "magnetoperception" than the other DEGs, were measured during the $2 \mathrm{~d}$ of exposure to the HMF. During the first $24 \mathrm{~h}$ of incubation, the expression of MAPK1,CCAR1, and CCNI initially increased before gradually decreasing (Figure 6A). Over this

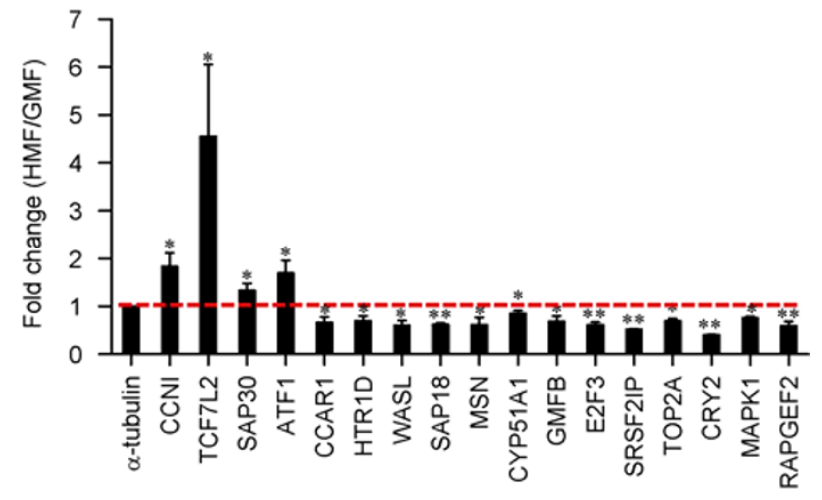

Figure 5 Verification of DEGs. The mRNA expression level of 17 verified DEGs. The fold changes are based on the ratio between the corresponding HMF and GMF samples. $\alpha$-Tubulin is the reference gene and the red dashed line indicates the point at which the ratio between the HMF and GMF samples is one. Data are mean \pm SEM. $n=3, n$ is the number of samples. ${ }^{*}, P<0.05 ; * *, P<0.01$.

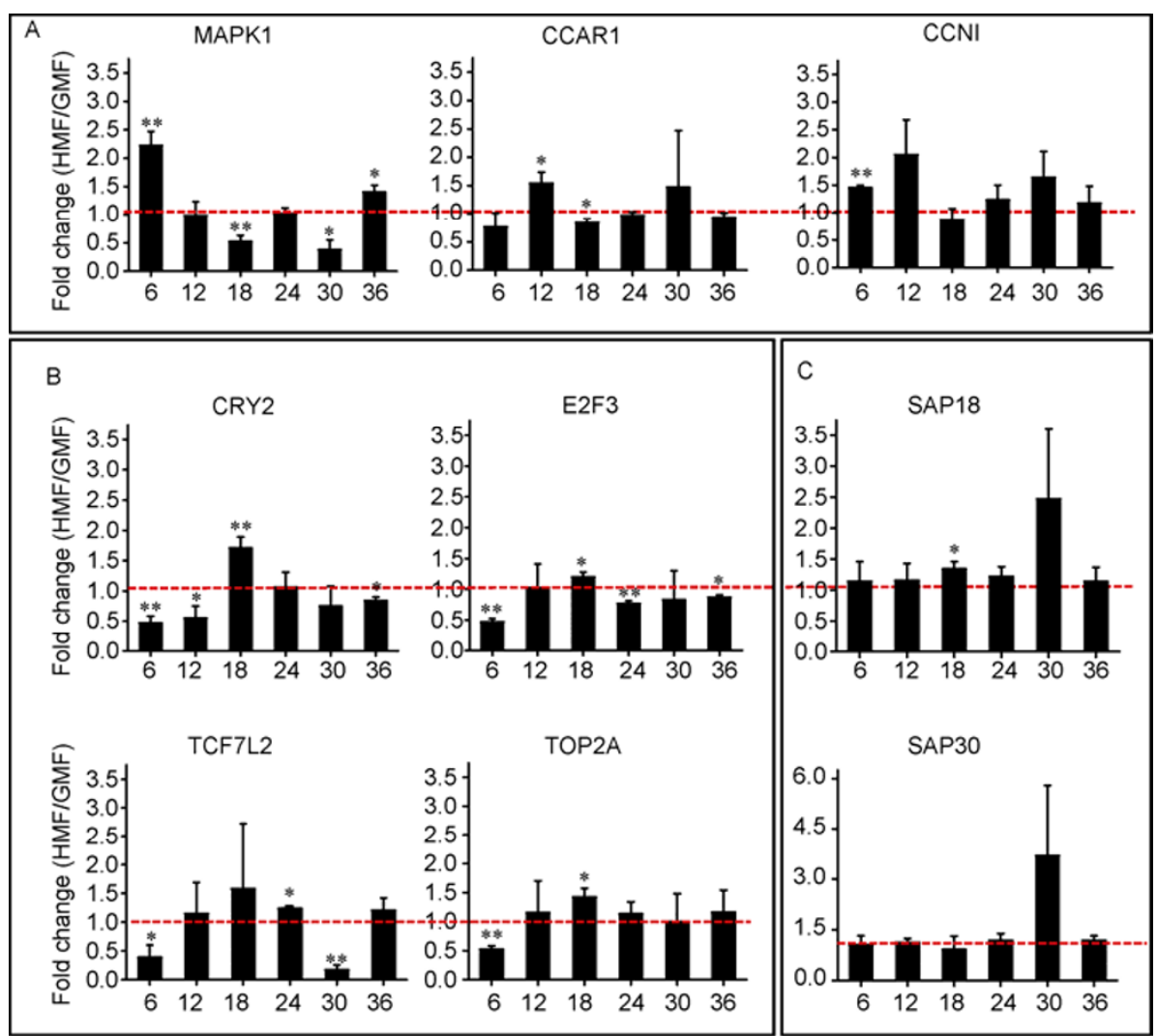

Figure 6 Dynamic expressions of DEGs. RNA samples were collected at 6, 12, 18, 24, 30 and 36 h. $\alpha$-Tubulin is the reference gene. The fold changes are based on the ratio between the corresponding HMF and GMF samples. The red dashed line indicates the point at which the ratio between the HMF and GMF samples is one. Genes showing similar patterns of expression changes are clustered into panel A, B, C, respectively. Data are mean \pm SEM. $n=3, n$ is the number of samples from parallel treatments experiments. *, $P<0.05 ; * *, P<0.01$. 
Table 3 Selected DEGs for the validation of gene expression ${ }^{\text {a) }}$

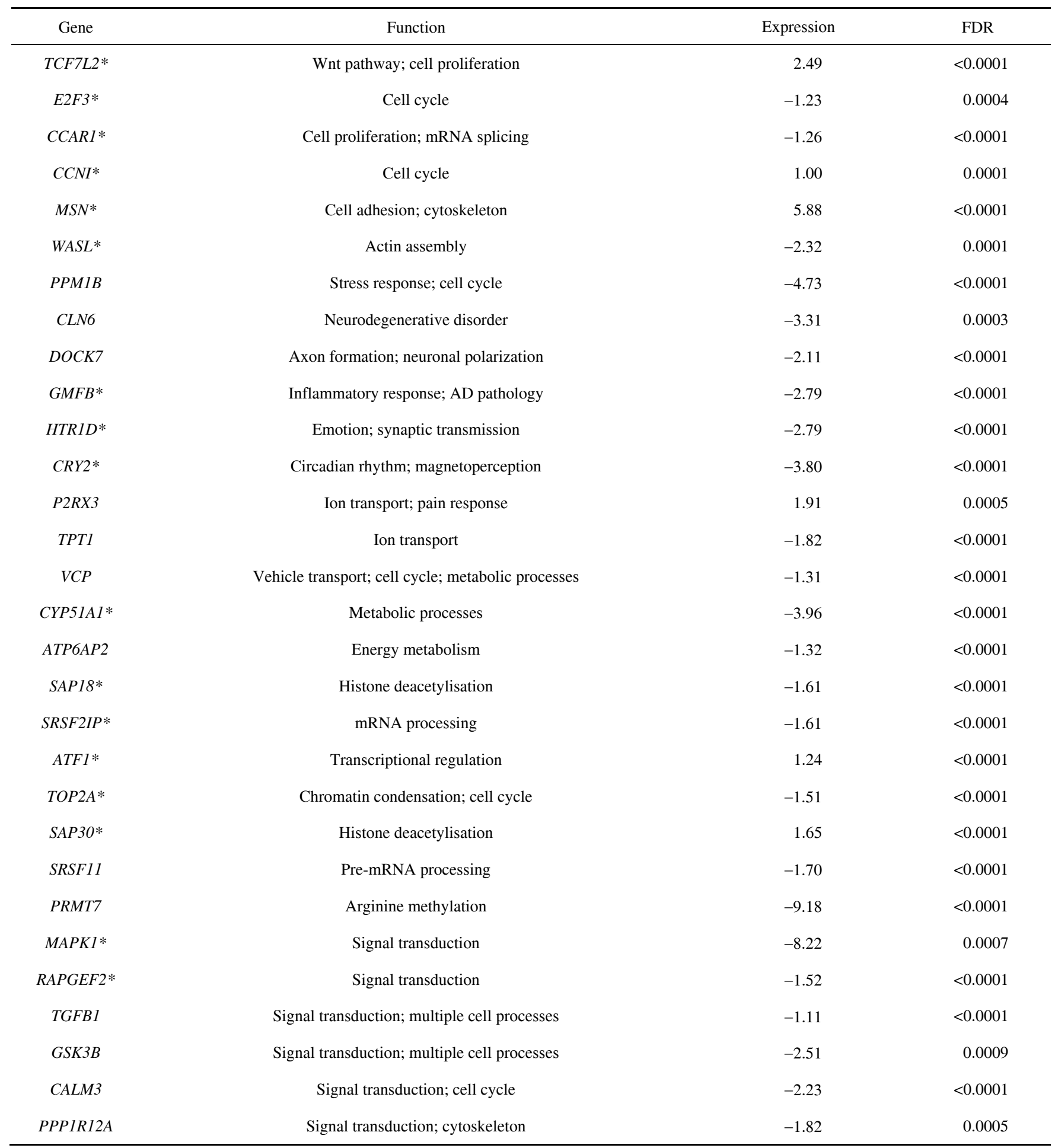

a) *, the DEGs verified by qPCR.

same 24-h timeframe, the expression of $C R Y 2, E 2 F 3$, $T C F 7 L 2$, and TOP $2 A$ was initially repressed, but then gradually increased and in some cases surpassed control levels of expression (Figure 6B). The changes in the expression of MAPK1 and $C R Y 2$ were the most striking. The expression of CCARI, CCNI, and TOP2A was generally unaffected from 24 to $36 \mathrm{~h}$ in the HMF (Figure 6A and B). After $30 \mathrm{~h}$ of HMF exposure, the expression of SAP18 and $S A P 30$ varied dramatically (Figure 6C). The expression of $M A P K 1, C R Y 2, E 2 F 3$ and TCF7L2 was repressed after $24 \mathrm{~h}$ in the HMF, but after $36 \mathrm{~h}$, the expression of TCF7L2 had recovered to control levels (Figure 6B), and MAPK1 ex- 
pression levels had significantly exceeded control levels (Figure 6A).

We plotted the relationships between the nine validated DEGs (Figure 7). As the function of CCNI and CRY2 in the cell proliferation network is not fully documented in the protein interaction network databases (BIND, BioGrid, HPRD, etc.) [36], the two genes are not shown in the relationship graph. Figure 7 shows that MAPK1 plays a central role in the expression regulation network of the verified DEGs, and suggests that the regulation of chromatin conformation and deacetylation might greatly contribute to the down-stream regulation of transcription and cell proliferation.

\section{Discussion}

\subsection{HMF exposure regulates multiple aspects of cell activities}

There is limited research published on the molecular mechanisms underlying the effects of the HMF. In this study, gene ontology (GO) and pathway analysis provided useful information about the response of human neuroblastoma (SH-SY5Y) cells to the HMF. We identified that the genes most significantly affected by the HMF were related to metabolic processes, cytoskeleton-related functions, signal transduction and brain function, and that the expression of most of these genes was repressed. Genes related to neurotransmitter transport were positively enriched, whereas genes related to neuron and neural crest cell migration, learning and memory, locomotion, and synaptic transmission were negatively enriched (Figure 2). These results are

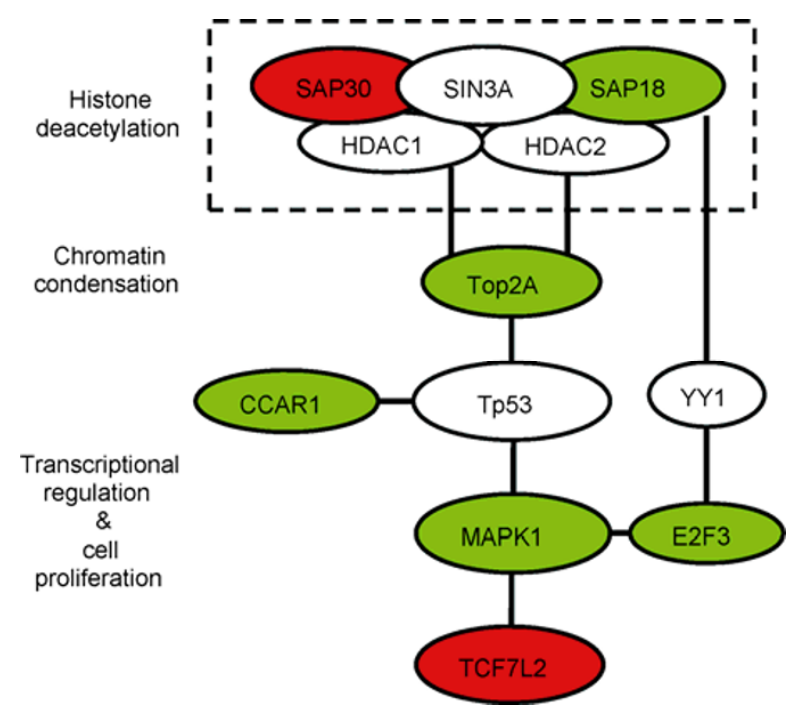

Figure 7 The relationship graph of DEGs. Verified up-regulated genes are colored red. Verified down-regulated genes are colored green. Non-DEGs are not colored. The dashed rectangle indicates the deacetylation-related genes. Genes of strong interactions were linked or overlapped in the graph. consistent with the reported adverse effects of the HMF on the central nervous system (CNS) [5].

By focusing on the terms "cell proliferation" and "apoptosis", we were able to gain a better understanding of the regulation of cell growth in the HMF. Most of the genes associated with cell proliferation, cell death, apoptosis, cell morphology, cell division, DNA regulation, and cell fate determination were down-regulated. After being exposed to the HMF for $2 \mathrm{~d}$, many processes that negatively regulate cell proliferation were suppressed; however, none of the processes that were positive for cell proliferation were up-regulated (Figure 3). We therefore hypothesize that the effect of the HMF is triggered by negative feedback regulation.

The results of the pathway analysis indicated that many metabolic pathways were significantly affected after exposure to the HMF (Figure 4). Pathways related to cytoskeleton assembly, cell adhesion, signal transduction, and brain function and disease were down-regulated (Figure 4). In particular, the notch pathway, which is known to play a critical role in embryonic development, cytoskeleton regulation and the regulation of cell death under metabolic stresses [47], was found to be up-regulated. The extent to which cellular processes are affected by HMF exposure suggests that the HMF targets many functions and signaling pathways.

\subsection{Novel clues to the molecular mechanism underly- ing the bio-response to $\mathrm{HMF}$}

The functions of the 17 validated DEGs provides a detailed view of the effect that $2 \mathrm{~d}$ of HMF exposure has on gene expression, as most of the expression changes were associated with cell proliferation and related functions, such as cell cycle, transcription and epigenetic regulation (Table 3, Figure 5). The expression of ATF1 [48,49], TCF7L2 [50,51] and $C C N I$ [52] (which positively influence cell proliferation) were the most strongly affected, and included $75 \%$ of the up-regulated genes. The promotion of G1-phase progression plays an important role in the HMF effect on cell proliferation [18], as an up-regulation of E2F3 (an important G1/S transition regulating gene [53]) was observed during the $2 \mathrm{~d}$ of HMF exposure. The decreased expression of the transcription regulators, $E 2 F 3$ and $C C A R 1$, provide a clue to the mechanism behind the extensive transcription repression that accompanied the increase in cell proliferation (Figure $5)$. The dynamic expression changes of CCARl during the early incubation period (12-18 h) (Figure 6) suggest that the HMF might affect hormone-induced transcriptional regulation processes [54,55], as this is the primary function of CCAR1. Expression changes were also verified in genes that are involved in genetic material modification and epigenetic 
control of gene expression, such as chromatin condensation (TOP2A) [56,57], histone acetylation [58] (SAP30 and SAP18 [59,60]), and alternative splicing (SRSF2IP [61,62]). Illustrating the relationship among these genes, namely the molecular network leading to changes in cell proliferation (Figure 7), as well as tracing the changes in gene expression during exposure to the HMF, will be helpful for our understanding of their roles.

Various cytoskeletal and photoreceptor proteins have previously been shown to respond to changes in the magnetic field, and as such, are referred to as magnetoreceptors $[19,24]$. We have found that the expression of two cytoskeleton-related genes, WASL and MSN, were down-regulated after $2 \mathrm{~d}$ of exposure to the HMF. WASL is an activator of the Arp2/3 complex leading to actin nucleation and is highly expressed in neural tissues [63]. MSN plays a crucial role in organizing membrane domains and provides structural links to strengthen the cell cortex [64]. Our results provide further evidence to support the hypothesis that the cytoskeleton can respond to magnetic fields [65]. The downregulation of CYP51A1 (one of the cytochrome P450 super family enzymes [66,67]) and CRY2 (a blue-light photoreceptor protein and a putative magnetoreceptor gene [24-26]) suggests that redox reactions and light-perception processes are involved in the bio-HMF response. As such, our results provide a link between the transcriptional changes that occur during exposure to the HMF and the putative magnetoreceptors that have previously been reported [19,24].

Of the 15 DEGs related to brain function $(P P M 1 B$, CLN6, DOCK7, GMFB, HTRID and CRY2), intracellular transport $(P 2 R E X 3, T P T 1$ and $V C P)$ and signal transduction (MAPK1, RAPGEF2, TGFB1, GSK3B, CALM and $P P P 1 R 2 A)$, only five (GMFB, HTRID, CRY2, MAPK1 and $R A P G E F 2$ ) were verified in the individual samples (Table 3, Figure 5), indicating an inconsistent response of these unverified genes to the HMF treatments. The variation in gene expression may be the result of small variations in the magnetic field of the HMF condition, which is difficult to abolish even within the small area that is used for cell culture (Figure S4 in Supporting Information). This 'noisy' background of treatments may also mask the importance of the verified changes.

Finally, as the GMFB gene (involved in reactive glia inflammation [68]) and HTRID gene (a serotonin receptor, and associated with depression [69,70]) were found to be down-regulated, inflammatory responses and the serotonin pathway may play a role in the bio-HMF response. The down-regulation of RAPGEF2 (the key link between cell surface receptors and RAS activation [71]) and MAPK1 (an integration point for multiple biochemical signals [72]) suggests that the Ras and MAPK pathway may also be affected by the HMF.

\subsection{Sequential changes in gene expression}

The dynamic response of selected DEGs indicates that cells respond very quickly to the changes in the magnetic environment. Previous research has shown that following seeding, cells experience an "early stationary phase" (involving a short period of adhesion followed by a stabilization period), after which they begin a logarithmic growth phase of proliferation [73]. As the cells were transferred to the HMF immediately after seeding, our results suggest that cells are sensitive to magnetic field changes within the early stationary stage. As such, it is not surprising that cell adhesion, cytoskeleton assembly, and biomolecule synthesis were affected by HMF exposure, as these processes are involved in the early stationary stage. Further support for this interpretation can be gleaned from the GO analysis, pathway analysis, and the dynamic expressions of the selected DEGs.

Within $6 \mathrm{~h}$ of the HMF exposure, $66 \%$ of the DEGs had undergone an alteration of their expression patterns compared with the control environment, including a rapid increase in the expression of MAPK1, suggesting that exposure to the HMF had a substantial influence on human neuroblastoma cells. While cells start to enter the logarithmic growth phase 18-30 h after seeding, previous research has shown that the progress of the cell cycle is more apparent in the $12-30 \mathrm{~h}$ period, compared with the $30-48 \mathrm{~h}$ period [18]. Therefore, the events that occur during this period are closely correlated with the pro-proliferative effect of the HMF. During the logarithmic growth phase between 18-30 h, we also observed a decrease in the expression of $77 \%$ of the DEGs, including a repression of $M A P K 1$ expression, which may be a compensatory response to the earlier rapid increase. In concert, these gene expression changes caused an acceleration of cell proliferation in the HMF.

From 30-48 h, the effect of the HMF on cell cycle progression weakened (G1-phase and S-phase) and in some cases even reversed (G2/M-phase). A short-term fluctuation from 32-36 h at S-phase was recorded in the HMF [18]. This event was very similar to the sudden expression change of MAPK1. Since MAPK1 was involved in 30 significantly enriched pathways (Table S1 in Supporting Information), it is possible that it acts as a central effector of the HMF signal during the early period of exposure, as indicated by the gene relationship graph (Figure 7).

The expression of CRY2 was initially reduced $(6 \mathrm{~h})$, which was followed by a rapid increase (12-18 h) and then a gradual decrease $(24-48 \mathrm{~h})$, indicating that $C R Y 2$ is involved in cell growth, as these time periods correspond to the early stationary stage and logarithmic growth phase. Investigations into clock genes have shown that the environmental light signals can be sent to the transcriptional machinery through the MAPK signaling pathway via the $C R Y$ genes [74,75]. Accelerated cell cycle progression of 
Cry-deficient fibroblasts has been observed in earlier studies [76]. It is reasonable to hypothesize that CRY can transduce the magnetic field signal using similar molecular pathways. Detailed structural and biochemical analysis of CRY proteins would elucidate how they may respond to changes in the magnetic environment.

Although the expression levels of the validated DEGs were in agreement with the sequencing results, we noticed that the fold change of some DEGs in the verification experiments was much lower than what was predicted by the sequencing data (Figure 5, Table 3). On the other hand, the fold change was also higher for some genes, namely TCF7L2 (18 and $48 \mathrm{~h})$, CCARl (30 h), SAP18 (30 h) and SAP30 (30 h). The variation of the GMF control might be the reason for this phenomenon. By comparing the magnetic field distributions of the GMF control shelf and the HMF chamber (Figure S4 in Supporting Information), we found the variation in the control group to be higher than that we observed in the HMF. Although the size of the petri dish (60 $\mathrm{mm}$ diameter) is small, the static magnetic field was not evenly distributed throughout this area. Furthermore, though the dishes containing cells in the control (GMF) environment were stacked in one place, the magnetic field at the bottom of each dish was found to vary. This variation could be a factor causing a relative large error bar in the gene sensitive to changes in the local magnetic field (Figure S4 in Supporting Information). In the future, the culture location of the GMF sample should be fixed, as should the time at which the work is conducted. In addition, the magnitudes of the AC fields were also different between the GMF and HMF conditions. Considering the fact that the AC magnetic field could affect the signal transduction in the MAPK pathway $[77,78]$, conducting experiments to discriminate between the effects of the AC and DC magnetic fields will add to our understanding of the mechanisms underlying the effects of the HMF.

\section{Conclusion}

By using massively parallel sequencing, $17 \mathrm{HMF}-$ responding DEGs were identified from RNA samples after being exposed to the HMF for $2 \mathrm{~d}$. We found that HMF exposure significantly affect the transcription of genes related to macromolecule transport, metabolic process and mRNA processing, and to the subsequent pathways involved in the organization of the cytoskeleton, regulation of chromatin condensation, transcription, and brain function. Dynamic changes in the expression of DEGs, especially in MAPKI and $C R Y 2$, were found during the first $24 \mathrm{~h}$ of HMF exposure, suggesting the involvement of the MAPK pathway and cryptochromes in mediating the HMF effect.
We thank Engineer Shi Qiang (National Space Science Center, Chinese Academy of Sciences) for his assistance in the measurement of the magnetic fields and Miss Ashley Cooper (Queensland Brain Institute, The University of Queensland) for her revision of the manuscript. We thank Dr. Guo XiangQian (Institute of Biophysics, Chinese Academy of Sciences) for his assistance with Illumina/Solexa sequencing. This work was supported by the Queensland-Chinese Academy of Sciences (QCAS) Biotechnology Fund (GJHZ1131), the Project of Chinese Academy of Sciences for the Development of Major Scientific Research Equipment (YZ201148), the National Natural Science Foundation of China (31200628), and the External Cooperation Program of Bureau of International Cooperation, Chinese Academy of Sciences (GJHZ201302).

1 Wiltschko W, Wilschko R. Magnetic orientation and magnetoreception in birds and other animals. J Comp Physiol A, 2005, 191: 675-693

2 Lohmann KJ, Lohmann CMF, Putman NF. Magnetic maps in animals: nature's GPS. J Exp Biol, 2007, 210: 3697-3705

3 Kopanev VI, Efimenko GD, Shakula AV. Biological effect of a hypogeomagnetic environment on an organism. Biol Bull Acad Sci USSR, 1979, 6: 289-298

4 Dubrov AP. The Geomagnetic Field and Life: Geomagnetobiology. New York: Plenum, 1989. Chapter 4 (translated from Russian by Sinclair FL)

5 Mo WC, Liu Y, He RQ. A biological perspective of the hypomagnetic field: from definition towards mechanism. Prog Biochem Biophys, 2012, 39: 835-842

6 Asashima M, Shimada K, Pfeiffer CJ. Magnetic shielding induces early developmental abnormalities in the newt, Cynops pyrrhogaster. Bioelectromagnetics, 1991, 12: 215-224

7 Mo WC, Liu Y, Cooper HM, He RQ. Altered development of Xenopus embryos in a hypogeomagnetic field. Bioelectromagnetics, 2012, 33: 238-246

8 Jiang JC, Jin HQ, Lin YF, Chen H, Yang XY, Zeng XP, Zhou X. Effect of magnetic free field space (MFFS) on vocal behavior in melop sittacus undulafus. Acta Seismol Sin, 1998, 20: 421-426

9 Bliss VL, Heppner FH. Circadian activity rhythm influenced by near zero magnetic field. Nature, 1979, 261: 411-412

10 Zamoshchina TA, Krivova NA, Khodanovich MIu, Trukhanov KA, Tukhvatulin RT, Zaeva OB, Zelenskaia AE, Gul' EV. Influence of simulated hypomagnetic environment in a far space flight on the rhythmic structure of rat's behavior (in Russian). Aviakosm Ekolog Med, 2012, 46: 17-23

11 Zhang B, Lu H, Xi W, Zhou X, Xu S, Zhang K, Jiang J, Li Y, Guo A. Exposure to hypomagnetic field space for multiple generations causes amnesia in Drosophila melanogaster. Neurosci Lett, 2004, 371: 190-195

12 Xu ML, Wang XB, Li B, Li DF, Jiang JC. Long-term memory was impaired in one-trial passive avoidance task of day-old chicks hatching from hypomagnetic field space. Chinese Sci Bull, 2003, 48: 2454-2457

13 Xiao Y, Wang Q, Xu ML, Jiang JC, Li B. Chicks incubated in hypomagnetic field need more exogenous noradrenaline for memory consolidation. Adv Space Res, 2009, 44: 226-232

14 Del Seppia C, Luschi P, Ghione S, Crosio E, Choleris E, Papi F. Exposure to a hypogeomagnetic field or to oscillating magnetic fields similarly reduce stress-induced analgesia in C57 male mice. Life Sci, 2000, 66: 1299-1306

15 Choleris E, Del Seppia C, Thomas AW, Luschi P, Ghione G, Moran GR, Prato FS. Shielding, but not zeroing of the ambient magnetic field reduces stress-induced analgesia in mice. Proc Biol Sci, 2002, 269: 193-201

16 Prato FS, Robertson JA, Desjardins D, Hensel J, Thomas AW. Daily repeated magnetic field shielding induces analgesia in CD-1 mice. 
Bioelectromagnetics, 2005, 26: 109-117

17 Binhi VN, Sarimov RM. Zero magnetic field effect observed in human cognitive processes. Electromagn Biol Med, 2009, 28: 310-315

18 Mo WC, Zhang ZJ, Liu Y, Bartlett PF, He RQ. Magnetic shielding accelerates the proliferation of human neuroblastoma cell by promoting G1-phase progression. PLoS ONE, 2013, 8: e54775

19 Wang DL, Wang XS, Xiao R, Liu Y, He RQ. Tubulin assembly is disordered in a hypogeomagnetic field. Biochem Biophys Res Commun, 2008, 376: 363-368

20 Martino CF, Perea H, Hopfner U, Ferguson VL, Wintermantel E. Effects of weak static magnetic fields on endothelial cells. Bioelectromagnetics, 2010, 31: 296-301

21 Martino CF, Portelli L, McCabe K, Ferguson VL, Wintermantel E. Reduction of the Earth's magnetic field inhibits growth rates of model cancer cell lines. Bioelectromagnetics, 2010, 31: 649-655

22 Belyaev I Ya, Alipov YD, Harms-Ringdahl M. Effects of zero magnetic field on the conformation of chromatin in human cells. Biochim Biophys Acta, 1997, 1336: 465-473

23 Martino CF, Castello PR. Modulation of hydrogen peroxide production in cellular systems by low level magnetic fields. PLoS ONE, 2011, 6: e22753

24 Foley LE, Gegear RJ, Reppert SM. Human cryptochrome exhibits light dependent magnetosensitivity. Nat Commun, 2011, 2: 356

25 Maeda K, Robinson AJ, Henbest KB, Hogben HJ, Biskup T, Ahmad M, Schleicher E, Weber S, Timmel CR, Hore PJ. Magnetically sensitive light-induced reactions in cryptochrome are consistent with its proposed role as a magnetoreceptor. Proc Natl Acad Sci USA, 2012, 109: 4774-4779

26 Xu CX, Xiao Y, Lv Y, Wu CZ, Zhang YX, Song T. A near-null magnetic field affects cryptochrome-related hypocotyl growth and flowering in Arabidopsis. AdvSpace Res, 2012, 49: 834-840

27 Green CD, Simons JF, Taillon BE, Lewin DA. Open systems: panoramic views of gene expression. J Immunol Methods, 2001, 250: $67-79$

28 Murcray CE, Lewinger JP, Gauderman WJ. Gene-environment interaction in genome-wide association studies. Am J Epidemiol, 2009, 169: 219-226

29 David JP, Coissac E, Melodelima C, Poupardin R, Riaz MA, Chandor-Proust A, Reynaud S. Transcriptome response to pollutants and insecticides in the dengue vector Aedes aegypti using next-generation sequencing technology. BMC Genomics, 2010, 11: 216

30 Zhang Y, Schulz VP, Reed BD, Wang Z, Pan X, Mariani J, Euskirchen G, Snyder MP, Vaccarino FM, Ivanova N, Weissman SM, Szekely AM. Functional genomic screen of human stem cell differentiation reveals pathways involved in neurodevelopment and neurodegeneration. Proc Natl Acad Sci USA, 2013, 110: 1236112366

31 Han Y, Zhang Y, Mei Y, Wang Y, Liu T, Guan Y, Tan D, Liang Y, Yang L, Yi X. Analysis of hepatitis B virus genotyping and drug resistance gene mutations based on massively parallel sequencing. J Virol Methods, 2013, 193: 341-347

32 Ma L, Nie L, Liu J, Song S, Sun M, Yang J, Yang Y, Fang X, Hu S, Zhao Y, Yu J. An RNA-seq-based gene expression profiling of radiation-induced tumorigenic mammary epithelial cells. Genom Proteom Bioinform, 2012, 10: 326-335

33 Morrissy AS, Morin RD, Delaney A, Zeng T, McDonald H, Jones S, Zhao Y, Hirst M, Marra MA. Next-generation tag sequencing for cancer gene expression profiling. Genome Res, 2009, 19: 1825-1835

34 Mo WC, Liu Y, Jiang YD, Zhai GJ, He RQ. A Magnetic shielded incubation system for investigating biological effects of hypomagnetic field. Space Med Med Eng, 2013, 26: 249-253

35 Li R, Li Y, Kristiansen K, Wang J. SOAP: short oligonucleotide alignment program. Bioinformatics, 2008, 24: 713-714

36 Audic S, Claverie JM. The significance of digital gene expression profiles. Genome Res, 1997, 7: 986-995

37 Benjamini Y, Yekutieli D. The control of the false discovery rate in multiple testing under dependency. Ann Statist, 2001, 29: 1165-1188

38 Hooper SD, Bork P. Medusa: a simple tool for interaction graph analysis. Bioinformatics, 2005, 21: 4432-4433

39 Gene Ontology Consortium. The gene ontology (GO) project in 2006. Nucleic Acids Res, 2006, 34: D322-326

40 Ashburner M, Ball CA, Blake JA, Botstein D, Butler H, Cherry JM, Davis AP, Dolinski K, Dwight SS, Eppig JT, Harris MA, Hill DP, Issel-Tarver L, Kasarskis A, Lewis S, Matese JC, Richardson JE, Ringwald M, Rubin GM, Sherlock G. Gene ontology: tool for the unification of biology. The Gene Ontology Consortium. Nat Genet, 2000, 25: 25-29

41 Dupuy D, Bertin N, Hidalgo CA, Venkatesan K, Tu D, Lee D, Rosenberg J, Svrzikapa N, Blanc A, Carnec A, Carvunis AR, Pulak R, Shingles J, Reece-Hoyes J, Hunt-Newbury R, Viveiros R, Mohler WA, Tasan M, Roth FP, Le Peuch C, Hope IA, Johnsen R, Moerman DG, Barabási AL, Baillie D, Vidal M. Genome-scale analysis of in vivo spatiotemporal promoter activity in Caenorhabditis elegans. Nat Biotechnol, 2007, 25: 663-668

42 Schlitt T, Palin K, Rung J, Dietmann S, Lappe M, Ukkonen E, Brazma A. From gene networks to gene function. Genome Res, 2003, 13: $2568-2576$

43 Kanehisa M, Goto S, Kawashima S, Okuno Y, Hattori M. The KEGG resource for deciphering the genome. Nucleic Acids Res, 2004, 32: D277-280

44 Yi M, Horton JD, Cohen JC, Hobbs HH, Stephens RM. Whole Pathway Scope: a comprehensive pathway-based analysis tool for high-throughput data. BMC Bioinform, 2006, 7: 30

45 Draghici S, Khatri P, Tarca AL, Amin K, Done A, Voichita C, Georgescu C, Romero R. A systems biology approach for pathway level analysis. Genome Res, 2007, 17: 1537-1545

46 Wang X, Spandidos A, Wang H, Seed B. PrimerBank: a PCR primer database for quantitative gene expression analysis, 2012 update. Nucl Acids Res, 2012, 40: D1144-11499

47 Greenwald I, Kovall R. Notch signaling: genetics and structure. WormBook, 2013, 17: 1-28

48 Boyle JJ, Johns M, Kampfer T, Nguyen AT, Game L, Schaer DJ, Mason JC, Haskard DO. Activating transcription factor 1 directs Mhem atheroprotective macrophages through coordinated iron handling and foam cell protection. Circ Res, 2012, 110: 20-33

49 Huang GL, Guo HQ, Yang F, Liu OF, Li BB, Liu XY, Lu Y, He ZW. Activating transcription factor 1 is a prognostic marker of colorectal cancer. Asian Pac J Cancer Prev, 2012, 13: 1053-1057

50 Jin T, Liu L. The Wnt signaling pathway effector TCF7L2 and type 2 diabetes mellitus. Mol Endocrinol, 2008, 2: 2383-2392

51 Korinek V, Barker N, Morin PJ, van Wichen D, de Weger R, Kinzler $\mathrm{KW}$, Vogelstein B, Clevers H. Constitutive transcriptional activation by a $\beta$-catenin-TCF complex in $\mathrm{APC}^{-/}$colon carcinoma. Science, 1997, 275: 1784-1787

52 Nagano T, Hashimoto T, Nakashima A, Hisanaga S, Kikkawa U, Kamada S. Cyclin I is involved in the regulation of cell cycle progression. Cell Cycle, 2013, 12: 2617-2624

53 Inoshita S, Terada Y, Nakashima O, Kuwahara M, Sasaki S, Marumo F. Regulation of the G1/S transition phase in mesangial cells by E2F1. Kidney Int, 1999, 56: 1238-1241

54 Seo WY, Jeong BC, Yu EJ, Kim HJ, Kim SH, Lim JE, Kwon GY, Lee HM, Kim JH. CCAR1 promotes chromatin loading of androgen receptor (AR) transcription complex by stabilizing the association between AR and GATA2. Nucleic Acids Res, 2013, 41: 8526-8536

55 Kim JH, Yang CK, Heo K, Roeder RG, An W, Stallcup MR. CCAR1, a key regulator of mediator complex recruitment to nuclear receptor 
transcription complexes. Mol Cell, 2008, 31: 510-519

56 Cobb J, Miyaike M, Kikuchi A, Handel MA. Meiotic events at the centromeric heterochromatin: histone $\mathrm{H} 3$ phosphorylation, topoisomerase II alpha localization and chromosome condensation. Chromosoma, 1999, 108: 412-425

57 Dovey M, Patton EE, Bowman T, North T, Goessling W, Zhou Y, Zon L. Topoisomerase II alpha is required for embryonic development and liver regeneration in zebrafish. Mol Cell Biol, 2009, 29: 3746-3753

58 Magnaghi-Jaulin L, Ait-Si-Ali S, Harel-Bellan A. Histone acetylation and control of the cell cycle. Prog Cell Cycle Res, 2000, 4: 41-47

59 Kuzmichev A, Zhang Y, Erdjument-Bromage H, Tempst P, Reinberg D. Role of the Sin3-histone deacetylase complex in growth regulation by the candidate tumor suppressor p33 (ING1). Mol Cell Biol, 2002, 22: 835-848

60 Pile LA, Schlag EM, Wassarman DA. The SIN3/RPD3 deacetylase complex is essential for $\mathrm{G}(2)$ phase cell cycle progression and regulation of SMRTER corepressor levels. Mol Cell Biol, 2002, 22: 4965-4976

61 Gui JF, Lane WS, Fu XD. A serine kinase regulates intracellular localization of splicing factors in the cell cycle. Nature, 1994, 369: 678-682

62 Tanner S, Stagljar I, Georgiev O, Schaffner W, Bourquin JP. A novel SR-related protein specifically interacts with the carboxy-terminal domain (CTD) of RNA polymerase II through a conserved interaction domain. Biol Chem, 1997, 378: 565-571

63 Padrick SB, Rosen MK. Physical mechanisms of signal integration by WASP family proteins. Annu Rev Biochem, 2010, 79: 707-735

64 Fehon RG, McClatchey AI, Bretscher A. Organizing the cell cortex: the role of ERM proteins. Nat Rev Mol Cell Biol, 2010, 11: 276-287

65 Gartzke J, Lange K. Cellular target of weak magnetic fields: ionic conduction along actin filaments of microvilli. Am J Physiol Cell Physiol, 2002, 283: C1333-1346

66 Lepesheva GI, Waterman MR. CYP51-the omnipotent P450. Mol Cell Endocrinol, 2004, 215: 165-170

67 Guengerich FP. Cytochrome p450 and chemical toxicology. Chem Res Toxicol, 2008, 21: 70-83

68 Thangavel R, Stolmeier D, Yang X, Anantharam P, Zaheer A.
Expression of glia maturation factor in neuropathological lesions of Alzheimer's disease. Neuropathol Appl Neurobiol, 2012, 38: 572-581

69 Wasserman D, Geijer T, Sokolowski M, Rozanov V, Wasserman J. Nature and nurture in suicidal behavior, the role of genetics: some novel findings concerning personality traits and neural conduction. Physiol Behav, 2007, 92: 245-249

70 Uher R, McGuffin P. The moderation by the serotonin transporter gene of environmental adversity in the aetiology of mental illness: review and methodological analysis. Mol Psychiatry, 2008, 13: 131-146

71 Rebhun JF, Castro AF, Quilliam LA. Identification of guanine nucleotide exchange factors (GEFs) for the Rap1 GTPase. Regulation of MR-GEF by M-Ras-GTP interaction. J Biol Chem, 2000, 275: 34901-34908

72 Seger R, Krebs EG. The MAPK signaling cascade. FASEB J, 1995, 9 726-735

73 Watanabe I, Okada S. Stationary phase of cultured mammalian cells (L5178Y). J Cell Biol, 1967, 35: 285-294

74 Cermakian N, Pando MP, Thompson CL, Pinchak AB, Selby CP, Gutierrez L, Wells DE, Cahill GM, Sancar A, Sassone-Corsi P. Light induction of a vertebrate clock gene involves signaling through blue-light receptors and MAP kinases. Curr Biol, 2002, 12: 844-848

75 Czarna A, Berndt A, Singh HR, Grudziecki A, Ladurner AG, Timinszky G, Kramer A, Wolf E. Structures of Drosophila cryptochrome and mouse cryptochrome 1 provide insight into circadian function. Cell, 2013, 153: 1394-1405

76 Destici E, Oklejewicz M, Saito S, van der Horst GT. Mammalian cryptochromes impinge on cell cycle progression in a circadian clock-independent manner. Cell Cycle, 2011, 10: 3788-3797

77 Martínez MA, Úbeda A, Cid MA, Trillo MÁ. The proliferative response of NB69 human neuroblastoma cells to a $50 \mathrm{~Hz}$ magnetic field is mediated by ERK1/2 signaling. Cell Physiol Biochem, 2012, 29: 675-686

78 Sheikh AQ, Taghian T, Hemingway B, Cho H, Kogan AB, Narmoneva DA. Regulation of endothelial MAPK/ERK signalling and capillary morphogenesis by low-amplitude electric field. J R Soc Interface, 2013, 10: 20120548

Open Access This article is distributed under the terms of the Creative Commons Attribution License which permits any use, distribution, and reproduction in any medium, provided the original author(s) and source are credited.

\section{Supporting Information}

Figure S1 Correlation analysis of the expression levels of $\alpha$-tubulin and 18S rRNA with the quantity of total RNA. The quantity of RNA input for cDNA synthesisis shown by electrophoresis. The gray values and the expression values of $\alpha$-tubulin and $18 \mathrm{~S}$ rRNA from qPCR test for the 6 and $12 \mathrm{~h}$ RNA samples are listed below the corresponding lanes of each sample. 1, 2 and 3 refer to the parallel samples of each group. The values were normalized to the "GMF 1" samples of each group. 18S rRNA: forward, CAGCCACCCGAGATTGAGCA; backward, TAGTAGCGACGGGCGGTGTG; temperature, 52 ${ }^{\circ}$; 1 length, $252 \mathrm{bp}$.

Figure S2 The sequencing saturation report. The percentage of identified genes became stagnant when 5.39 million reads from the HMF samples (A) and 7.97 million reads from the GMF samples (B) were obtained.

Figure S3 Accelerated proliferation of SH-SY5Y cells in the HMF. SH-SY5Y cells were seeded in $60 \mathrm{~mm}$ petri dishesat $1.5 \times 10^{4} \mathrm{~cm}^{-2}$ and incubated in the HMF/GMF for $2 \mathrm{~d}$. A and B, Phase-contrast pictures of cells in the GMF (A) and HMF (B) at day 2 . Scale bar, $100 \mu \mathrm{m}$. C, Cell densities determined by hemocytometry at day $2 . *, P<0.05$ by one-way ANOVA; data are represented as mean $\pm \mathrm{SD} ; n=3, n$ is the number of experiments 
Figure S4 The magnetic field conditions for cell culture. The distributions of the magnetic fields in the magnetic shielding box (A) and the bottom layer of the control shelf (B) were plotted according to the vector sum of the magnetic field measurements. The HMF exposed cells were incubated at places with residue magnetic field lower than $200 \mathrm{nT}$ (the white dashed rectangles). The control cells were incubated at places with magnetic fieldshigher than $13 \mu \mathrm{T}$ (the blue dashed rectangles).

The supporting information is available online at life.scichina.com and link.springer.com. The supporting materials are published as submitted, without typesetting or editing. The responsibility for scientific accuracy and content remains entirely with the authors. 